\title{
The Chemical Composition of the Mandibular Gland Secretion of Melipona bicolor Lepeletier, 1836 (Hymenoptera, Apidae, Meliponini): A Comparative Study Among Castes and Sexes
}

\author{
Luciana F. Gracioli-Vitti*, ${ }^{*}$, Fábio C. Abdalla ${ }^{a}$, Regina L. M. Silva de Moraes ${ }^{a}$ and Graeme R. Jones ${ }^{b}$ \\ ${ }^{a}$ Departamento de Biologia, Instituto de Biociências, Universidade Estadual Paulista, Av. 24A, 1515, \\ 13506-900 Rio Claro - SP, Brazil \\ ${ }^{b}$ School of Chemistry and Physics, Lennard-Jones Laboratories, Keele University, Staffordshire, ST5 5BG, UK
}

\begin{abstract}
A secreção das glândulas mandibulares de operárias recém-emergidas, aprovisionadoras de cria e forrageiras, rainhas virgens e fisogástricas e machos de Melipona bicolor foi analisada através de cromatografia gasosa-espectrometria de massas. Foi verificado que a secreção é composta por uma mistura de hidrocarbonetos, álcoois, ésteres e ácidos. A secreção é casta-sexo específica e difere, também, de acordo com a tarefa desenvolvida pelas operárias e condição fisiológica reprodutiva das rainhas.
\end{abstract}

The mandibular gland secretions of newly emerged, nurse and forager workers, virgin and physogastric queens and males of Melipona bicolor were analyzed by gas chromatography-mass spectrometry. The secretion is composed of a blend of hydrocarbons, alcohols, esters, and acids. The secretion is caste-sex specific and also differs with the tasks performed by the workers and the physiological reproductive condition of the queens.

Keywords: GC-MS, mandibular glands, Melipona bicolor, caste, sex, reproductive variation.

\section{Introduction}

Colonies of eusocial bees include males and females, the latter being represented by two castes: workers and queens. The main function of the males is to mate with the queen and, therefore, supply the genetic complementation for female reproduction. The queen influences the behavior and physiology of the infertile females or workers ${ }^{1,2}$ that are responsible for every task of colony maintenance, such as nest defense, provisioning, and brood care. ${ }^{3}$

In the colony darkness a precise system of chemical communication exists to maintain the interaction among individuals and the organization of the various activities. This chemical communication is based on the production of substances with intra-specific action known as pheromones ${ }^{4}$ by numerous exocrine glands dispersed along the bee body. ${ }^{5}$

The main function of the pheromones produced by the mandibular gland of Apis mellifera honeybee workers is alarm or defense. In contrast, males use their mandibular gland to produce sexual attractants for the queens. The

*e-mail: lucifg@rc.unesp.br queen produces the "queen substance", ${ }^{6}$ a primer pheromone used to prevent worker ovary development and for sexual attraction of males., ${ }^{1,6,7}$

Among the workers, there are variations in the composition of the glandular product related to age and type of task performed. Young workers produce mainly 10-hydroxydecenoic acid while older ones, whose task is foraging, produce predominantly 2-heptanone..$^{8-10}$

In spite of the differences between the glandular products of queens and workers, the same biosynthetic pathways for the production of pheromones is potentially present in both, since it was demonstrated that egg-laying workers of A. mellifera and A. mellifera capensis also produce 9-oxydecenoic acid, which is one of the components of the queen's mandibular gland secretion. ${ }^{11}$ Therefore, the presence of the queen in A. mellifera apparently inhibits in workers ${ }^{12}$ the production of pheromones typical of the reproductive female.

In meliponine bees, mandibular glands occur in queens, workers, and males. ${ }^{13}$ Whereas in A. mellifera the queens possess larger mandibular glands, in Meliponini these glands are more developed in the workers. ${ }^{14}$ Little is known about the possible functions of the mandibular glands in meliponines. In Trigona postica, foraging workers use the 
mandibular gland secretion as a trail pheromone to mark the way to food sources. ${ }^{15}$

In order to better understand the role of the mandibular glands in the social organization of meliponines, the chemical composition of the mandibular glands was analyzed in newly emerged, nurse and forager workers, as well as in males and in virgin and physogastric queens of Melipona bicolor, a facultative polygynic species. ${ }^{16}$

\section{Materials and Methods}

For this study, 10 pairs of mandibles and mandibular glands were used for each group: newly emerged, nurse and forager workers, males, and virgin queens of Melipona bicolor Lepeletier, 1836 (Hymenoptera, Meliponini). Only one pair of mandibles and mandibular glands was available for physogastric queens, that are difficult to obtain, as much by the rarity of this species in São Paulo State as for the great difficulty to maintain the colonies in artificial condition. Frequently queen withdrawal led to colony death. The individuals were collected from different polygynic colonies.

Immediately after collection, all bees were transferred to an amber vial and placed in the refrigerator for $5 \mathrm{~min}$ to immobilize them and avoid the emptying of their glands at the moment of dissection, as a result of stress.

The bees were dissected in distilled water and the glands transferred to a soft soda glass capillary $(1 \mathrm{~mm}$ diameter) and sealed in a flame for subsequent analysis by GC/MS. ${ }^{17-19}$ Samples were stored in a freezer prior to analysis.

Extracts of the glands were made by breaking the sealed capillary in $30 \mu \mathrm{L}$ of hexane and crushing the capillary to get the solution with the gland extract. From this solution, $1 \mu \mathrm{L}$ was injected into a gas chromatograph - mass spectrometer.

The mandibular glands were always manipulated and analyzed together with their respective mandibles, thus, "mandibular glands" should be understood as the whole mandibles plus glands. For this reason, isolated mandibles were analyzed as control, in order to evaluate the degree of interference of their chemical compounds in the final chemical composition.

\section{Analysis of the samples}

The analytical separation was accomplished directly in a Hewlett-Packard 5890A gas chromatograph coupled to a selective mass detector series 5970B (quadrupole spectrometer, using $70 \mathrm{eV}$ of electric impact for ionization). The system was controlled and the data accumulated in a
Hewlett-Packard microcomputer series 300 connected to a HP 5971/5972 MSD Chemstation. The analyses were made on a $30 \mathrm{~m}$ fused silica column Rtx-5 (30 m x 0.37 $\mathrm{mm} \times 0.5 \mathrm{~mm}$ ) coated with Poly (5\%-biphenyl-95\% dimethyl) siloxane.

The oven was programmed to reach a final temperature of $325^{\circ} \mathrm{C}$ starting from an initial temperature of $60{ }^{\circ} \mathrm{C}$ and increasing at a rate of $10^{\circ} \mathrm{C} / \mathrm{min}$. Helium was used as carrier gas with a flow of $1 \mathrm{~mL} / \mathrm{min}$. Injection was made in the splitless mode with a purge off time of $0.75 \mathrm{~min}$ and solvent delay time of $5 \mathrm{~min}$ before the mass spectrometer was switched on. The mass detector was programmed to detect a minimum mass of $35 \mathrm{Da}$ up to a maximum mass of $550 \mathrm{Da}$.

\section{Interpretation of the data}

The chemical compounds were identified by the interpretation of their mass spectra, by comparison with MS-Databases, ion fragmentation pattern and searching the NBS Library of Spectra of Mass and Mass Spectral Register (Stenhagen, Abrahamsson and McLafferty; J. Wiley and Sons).

An external standard solution was provided by a mixture of 12 different synthetic hydrocarbons (C16, C18, C19, C20, C21, C22, C23, C24, C25, C28, C30). Immediately after the injection of an extract, $1 \mu \mathrm{l}$ of the external standard solution was injected to compare the retention time of the hydrocarbons detected in the extract.

\section{Results}

The mandibular glands of $M$. bicolor presented a plethora of oxygenated compounds and hydrocarbons (Tables 1,2). The more frequent hydrocarbons which were found in all bees analysed of both castes were C23, C25:1, C25, C27:1, C27, C29:1, C31:1, with C27:1 the most abundant. These hydrocarbons were found in both mandibular glands and mandibles in different proportions. Alcenes were usually more abundant than the respective alcanes (Tables 1, 2).

Males, newly emerged workers and virgin queens showed a great variety of compounds in the mandibular glands (Tables 1, 2). Nurse and forager workers showed fewer compounds in the mandibular glands than the other castes (Tables 1, 2)

In the workers, 2-heptanone and 2-heptanol were present in newly emerged, nurse and forager workers. The amide oil was absent from foragers, while 2-dodecanone and octadecenoic acid were present only in these bees (Table 1). Linoleic acid was found only in newly emerged workers (Table 1). 
Table 1. Relative abundance (\%) of the main chemical compounds in the mandibular glands secretion of males (MG-MALES), newly emerged workers (MG-NEW), provisioning workers (MG-PW) and foraging workers (MG-FW) and mandibles (MAND) of Melipona bicolor

\begin{tabular}{|c|c|c|c|c|c|c|}
\hline Retention time & Compounds & $\begin{array}{c}\text { MG-MALES } \\
\%\end{array}$ & $\begin{array}{c}\text { MG-NEW } \\
\%\end{array}$ & $\begin{array}{c}\text { MG-PW } \\
\%\end{array}$ & $\begin{array}{c}\text { MG-FW } \\
\%\end{array}$ & $\begin{array}{c}\text { MAND } \\
\%\end{array}$ \\
\hline 6.70 & 2-Heptanone & 5.00 & Traces & 0.63 & 0.89 & - \\
\hline 6.79 & 1-Heptanol & Traces & - & - & Traces & - \\
\hline 6.88 & 2-Heptanol & Traces & 2.55 & 1.13 & 2.11 & - \\
\hline 11.15 & Not confirmed & - & - & Traces & Traces & - \\
\hline 19.59 & 2-Dodecanone & - & - & - & 1.11 & - \\
\hline 23.98 & n-Uncosene $(\mathrm{C} 21: 1)$ & - & Traces & - & - & - \\
\hline 23.99 & Uncosane $(\mathrm{C} 21)$ & - & Traces & - & - & - \\
\hline 24.00 & Docosane (C22) & - & Traces & - & - & - \\
\hline 24.09 & 8-Dodecenol & - & Traces & - & - & - \\
\hline 25.71 & n-Tricosene (C23:1) & 3.60 & - & - & - & 2.50 \\
\hline 25.82 & Tricosane $(\mathrm{C} 23)$ & 3.20 & 2.27 & 5.13 & 1.89 & 6.50 \\
\hline 25.89 & Tetracosane (C24) & - & 0.73 & Traces & Traces & - \\
\hline 26.27 & Not confirmed & - & 1.00 & - & - & - \\
\hline 26.67 & Amide oil & 1.00 & 2.36 & 2.00 & - & - \\
\hline 26.69 & Not confirmed & - & - & Traces & - & - \\
\hline 26.75 & Not confirmed & - & - & Traces & - & - \\
\hline 26.84 & Hexadecenoic acid & 12.40 & - & - & - & - \\
\hline 26.99 & Not confirmed & - & - & Traces & - & - \\
\hline 27.35 & Not confirmed & - & - & Traces & - & - \\
\hline 27.48 & n-Pentacosene (C25:1) & 16.80 & 3.09 & 5.00 & 9.78 & 9.00 \\
\hline 27.60 & Pentacosane (C25) & 6.60 & 5.82 & 7.63 & 7.11 & 10.00 \\
\hline 27.67 & 11,14,17 Eicosatrienoic acid & - & - & Traces & - & - \\
\hline 27.94 & $9,11,13-\mathrm{C} 25$ & - & 1.00 & - & - & - \\
\hline 28.07 & $5-\mathrm{C} 25$ & - & Traces & - & - & - \\
\hline 28.18 & Oleic acid & 1.20 & - & - & - & - \\
\hline 28.21 & Not confirmed & - & - & 1.00 & 1.00 & - \\
\hline 28.25 & Linoleic acid & - & 1.27 & - & - & - \\
\hline 28.27 & $9,12,15$-octadecatrienoic acid & 1.40 & Traces & 0.50 & 0.56 & - \\
\hline 28.28 & n-Hexacosene $(\mathrm{C} 26: 1)$ & - & 0.45 & - & 0.56 & - \\
\hline 28.33 & Octadecenoic acid & - & - & - & 0.44 & - \\
\hline 28.36 & Hexacosane (C26) & - & 1.45 & Traces & Traces & - \\
\hline 28.42 & Not confirmed & - & Traces & - & - & - \\
\hline 28.46 & $?-\mathrm{C} 26$ & - & Traces & - & - & - \\
\hline 28.54 & $5-\mathrm{C} 26$ & - & 0.73 & - & - & - \\
\hline 29.03 & (2)-7-Dodecenol & - & 0.91 & - & - & - \\
\hline 29.13 & n-Heptacosene (C27:1) & 22.20 & 47.82 & 54.50 & 42.22 & 7.50 \\
\hline 29.22 & Heptacosane (C27) & 5.00 & 5.91 & 5.13 & 6.33 & 6.00 \\
\hline 29.53 & $11,15-\mathrm{C} 27$ & - & 5.25 & - & - & - \\
\hline 29.67 & $5-\mathrm{C} 27$ & - & 0.55 & - & - & - \\
\hline 29.74 & n-Octacosene (C28:1) & 0.80 & - & - & Traces & - \\
\hline 29.82 & Octacosane (C28) & Traces & 2.09 & - & Traces & - \\
\hline 29.85 & 9-Octadecenoic acid & - & - & - & 0.44 & - \\
\hline 30.06 & $?-\mathrm{C} 28(1)$ & - & 0.45 & - & - & - \\
\hline 30.12 & $?-\mathrm{C} 28(2)$ & - & 0.91 & - & - & - \\
\hline 30.35 & n-Nonacosene $(\mathrm{C} 29: 1)$ & 2.40 & 7.82 & 12.13 & 20.56 & - \\
\hline 30.44 & Nonacosane (C29) & 0.60 & 0.45 & Traces & 1.00 & - \\
\hline 31.20 & $?-\mathrm{C} 29$ & - & 0.45 & - & - & - \\
\hline 30.47 & Squalene terpene & 11.20 & 0.73 & 0.63 & - & 45.00 \\
\hline 30.62 & 9-Octadecenol & - & - & - & 0.44 & - \\
\hline 30.79 & n-Untriacontene $(\mathrm{C} 31: 1)$ & 3.60 & 3.36 & 2.50 & 1.22 & 6.50 \\
\hline 30.86 & Untriacontane $(\mathrm{C} 31)$ & 1.40 & Traces & 0.13 & 0.56 & 7.50 \\
\hline 31.87 & Tritriacontane (C33) & - & Traces & - & - & - \\
\hline 32.95 & Pentriacontane (C35) & - & Traces & - & - & - \\
\hline
\end{tabular}

Traces, $<0.4 \%,-$, chemical compound not found. Indeterminate substances were included in the total percentage. 
Table 2. Relative abundance (\%) of the main chemical compounds in the mandibular glands secretion of virgin queens (MG-VQ) and physogastric queens (MG-PQ) of Melipona bicolor

\begin{tabular}{|c|c|c|c|}
\hline $\begin{array}{l}\text { Retention } \\
\text { Time }\end{array}$ & Compounds & $\begin{array}{c}\text { MG-VQ } \\
\%\end{array}$ & $\begin{array}{c}\text { MG-PQ } \\
\%\end{array}$ \\
\hline 6.70 & 2-Heptanone & 1.00 & -- \\
\hline 6.91 & 2-Heptanol & 6.11 & -- \\
\hline 8.35 & 1-Heptene (?) & Traces & -- \\
\hline 8.95 & 1-Heptanol & Traces & -- \\
\hline 10.89 & 1-Pentanol & Traces & -- \\
\hline 10.96 & 1-Butanol (?) & Traces & -- \\
\hline 11.05 & Pentenol (?) & Traces & -- \\
\hline 20.22 & Not confirmed & 0.67 & -- \\
\hline 23.27 & Not confirmed & 0.44 & - \\
\hline 23.99 & n-Uncosene $(\mathrm{C} 21: 1)$ & 0.67 & -- \\
\hline 24.07 & 9-Hexadecenoic acid & 4.11 & -- \\
\hline 25.75 & $\mathrm{n}$-Tricosene $(\mathrm{C} 23: 1)$ & 2.89 & -- \\
\hline 25.87 & Tricosane $(\mathrm{C} 23)$ & 6.33 & -- \\
\hline 26.13 & 1,5-Pentanediol (?) & 0.56 & -- \\
\hline 26.25 & Not confirmed & 1.89 & -- \\
\hline 26.33 & Not confirmed & 0.67 & -- \\
\hline 26.43 & Not confirmed & Traces & -- \\
\hline 26.70 & Amide oil & 8.00 & -- \\
\hline 26.76 & Not confirmed & Traces & - \\
\hline 26.87 & Not confirmed & 1.22 & -- \\
\hline 26.91 & Not confirmed & Traces & -- \\
\hline 27.05 & Not confirmed & 0.56 & -- \\
\hline 27.13 & Not confirmed & Traces & -- \\
\hline 27.23 & Not confirmed & 0.89 & -- \\
\hline 27.38 & Not confirmed & 0.11 & -- \\
\hline 27.43 & Propanol (?) & 1.78 & -- \\
\hline 27.47 & Not confirmed & 1.44 & -- \\
\hline 27.48 & n-Pentacosene $(\mathrm{C} 25: 1)$ & 17.33 & 2.00 \\
\hline 27.62 & Pentacosane $(\mathrm{C} 25)$ & 6.11 & 12.00 \\
\hline 28.23 & Linoleic acid & 3.89 & -- \\
\hline 28.29 & Not confirmed & 1.56 & - \\
\hline 28.35 & $9,12,15$-Octadecatrienoic acid & 1.78 & -- \\
\hline 28.87 & 9-Octadecenoic acid & 2.22 & - \\
\hline 29.14 & n-Heptacosene (C27:1) & 16.89 & 27.00 \\
\hline 29.26 & Heptacosane (C27) & 2.89 & 10.00 \\
\hline 29.46 & $?-\mathrm{C} 27$ & - & 3.00 \\
\hline 29.65 & $?-\mathrm{C} 27$ & Traces & 1.00 \\
\hline 29.85 & Octacosane (C28) & - & 10.00 \\
\hline 29.99 & $?-\mathrm{C} 28$ & - & 2.00 \\
\hline 30.05 & $? \mathrm{C}-28$ & - & 4.00 \\
\hline 30.52 & Squalene & 5.11 & 4.00 \\
\hline 30.70 & n-Nonacosene (C29:1) & - & 22.00 \\
\hline 30.84 & Nonacosane (C29) & - & 3.00 \\
\hline
\end{tabular}

Traces, $<0.4 \%,-$, chemical compound not found. Indeterminate substances were included in the total percentage.

Males contained a greater variety of oxygenated compounds than workers, with 1-heptanol, hexadecenoic acid and oleic acid being found exclusively in their mandibular glands (Table I).

Virgin queens showed a greater variety of compounds in their mandibular glands than physogastric queen including the main hydrocarbons and oxygenated compounds found in other bees (Tables 1,2) and some specific ones, such as 9,12,15-octadecatrienoic acid and 9-octadecenoic acid (Tables 1, 2).
Physogastric queen showed no oxygenated compounds in their mandibular glands, curiously having a greater amount of long-chain hydrocarbons (Table 2).

\section{Discussion}

The mandibular glands of $M$. bicolor show castespecific morphological differences and also differ between virgin and physogastric queens..$^{20}$ The results from the chromatographic analyses indicate a different chemical composition of the mandibular glands in relation to age and activity inside the colony for workers, and in relation to the physiological condition for queens. Males can also be distinguished from females by the chemical composition of the mandibular gland. These characteristics in $M$. bicolor show great similarity to the compounds found in Apis mellifera, though they differ in several aspects of sociality.

The hydrocarbons C23, C25:1, C25, C27, C29:1 and $\mathrm{C} 29$ in the mandibular gland extracts might be of cuticular origin since they were also found in the cuticle of nonemerged workers of M. bicolor and constitute structural hydrocarbons. ${ }^{21}$ This great variety of hydrocarbons could have also been derived from the cuticle that surrounds the lumen of all exocrine glands. The cuticular hydrocarbons became less variable according to the age increasing of the bees.

Nurse and forager workers presented very similar chemical compositions of the mandibular glands, but in the foragers some compounds are absent and others, like 2-dodecanone and octadecenoic acid, appear. These last two compounds are also present in virgin queens. The compounds with high volatility in foragers might act as alarm substances, which are most needed by the bees that perform tasks outside the colony. For other activities, such as marking the entrance to the nest and food sources, the volatility of the compounds must be low.

The compounds 2-heptanone and 9,12,15-octadecatrienoic acid are present in the extracts of the mandibular glands of all workers studied (newly emerged, provisioning, and foragers), the males and the virgin queens. The second compound seems to be related to aggressive behavior in A. mellifera, while 2-heptanone acts as an alarm pheromone. The absence of 2-heptanone in physogastric queen and its high percentage in the foraging workers might indicate that this compound also has an alarm function in M. bicolor.

Newly emerged workers and virgin queens showed linoleic acid in the mandibular gland extract. Birch $^{22}$ considered this compound as an elicitor for aggregation behavior in the beetle Trogoderma granarium. 
A series of complex oxygenated compounds were found to be exclusive of virgin queens. These compounds might be involved in the integration of these queens in the colony, allowing them to coexist in peace with the other members. The variety of compounds in the gland extracts of virgin queens can only be compared to those of newly emerged workers. This observation supports the hypothesis stated above, since both types of individuals lack a defined position inside the colony. On the other hand, the physogastric queen, who has a well-established function in the colony, exhibited a low variety of glandular compounds, all present in high amounts. Among these compounds, the main components of the secretion of the mandibular glands of queens of A. mellifera (9-oxydecenoic and 9hydroxydecenoic acids) were not detected. The compound characteristic of the secretion of the mandibular glands of workers of A. mellifera, 10-hydroxydecenoic acid, was also absent in the glands of the physogastric queen.

The role of males in bee colonies is strictly reproduction. Vetter and Visscher ${ }^{23}$ designated the males of $A$. mellifera as "winged spermatozoa", since the males leave the colony in search of a queen, mate, and die.

The restricted function of males inside colonies of Melipona is one of the main reasons to justify the existence of so few studies concerning the physiology of these individuals. Males are scarce in these colonies because when the queen leaves for the mating flight, she is mated by a single male (monogamy) and stores the spermatozoa inside a spermatheca. ${ }^{24}$ Therefore, according to our results, the hexadecenoic acid (12.40\%) and oleic acid (1.20\%) found exclusively in the mandibular gland secretion of males might be involved in sexual behavior, acting as sex pheromones.

In general, we conclude that the secretion of the mandibular glands differed, quantitatively and qualitatively, among the groups of individuals studied. In comparison to the glands, the isolated mandibles are extremely poor in chemical compounds, thus showing their low interference in the glandular composition results. Although several chemical compounds were found to be common to all the groups of individuals analyzed, our results allowed the recognition of specific compounds within each group, which are related to gender or caste. In addition, the results also showed the presence of hydrocarbons and structural terpenoids.

\section{Acknowledgments}

The authors thank Carminda da Cruz-Landim for her valuable suggestions and corrections and FAPESP for financial support.

\section{References}

1. Butler, C.G.; Insects Sociaux 1957, 4, 211.

2. Pain, J.; Ann. Abeille. 1962, 4, 73.

3. Free, J.B.; A Organização Social das Abelhas (Apis), EDUSP: São Paulo, 1980, p. 79.

4. Wilson, E.O.; Sci. Amer. 1963, 208, 100.

5. Cruz-Landim, C.; Abdalla, F.C.; Glândulas Exócrinas das Abelhas, FUNPEC: Ribeirão Preto, 2002, p. 181.

6. Butler, C.G.; Simpson, J.; Proc. Roy. Entomol. Soc. 1958, 33, 1200.

7. Butler, C.G.; Calam, D.H.; Callow, R.K.; Nature 1967, 213, 423.

8. Callow, R.K.; Johnston, N.C.; Simpson, J.; Experientia 1959, $15,421$.

9. Butler, C.G.; Nature 1966, 212, 530.

10. Crewe, R.M.; South African. J. Sci. 1976, 72, 209.

11. Crewe, R.M.; Velthuis, H.H.W.; Naturwissenschaften 1980, 67 , 467.

12. Moritz, R.F.A.; Crewe, R.M.; Hepburn, H.R.; Insects Sociaux 2002, 49, 86 .

13. Cruz-Landim, C.; Arq. Zool. São Paulo 1967, 15, 177.

14. Cruz-Landim, C.; Ferreira, A.; J. Kans. Entomol. Soc. 1968, $41,474$.

15. Lindauer, M.; Kerr, W.E.; Bee World 1960, 41, 29.

16. Bego, L.R.; Braz. J. Med. Biol. Res. 1989, 22, 587.

17. Morgan, E.D.; Wadhams, L.J.; J. Chromatographic Sci. 1972, 10, 528 .

18. Morgan, E.D.; Anal. Chim. Acta 1990, 236, 227.

19. Jones, G.R.; Oldham, N.J.; J. Chromatogr. A 1999, 843, 199.

20. Gracioli, L.F.; Silva de Moraes, R.L.M.; Sociobiology 2002, $40,449$.

21. Abdalla, F.C.; Jones, G.R.; Morgan, E.D.; Cruz-Landim, C.; Genet. Mol. Res. 2003, 2, 191.

22. Birch, M.C.; Pheromones, North-Holland Publishing Company: Amsterdam, 1974, p. 495.

23. Vetter, R.S.; Visscher, P.K.; J. Chem. Ecol. 1997, 23, 1867.

24. Kerr, W.E.; Zucchi, R.; Nakadaira, J.K.; Butulo J.E.; J. New York Entomol. Soc. 1962, 70, 265.

Received: June 5, 2003

Published on the web: August 17, 2004

FAPESP helped in meeting the publication costs of this article. 